\title{
Life Cycle Sustainability Assessment-A Survey Based Potential Future Development for Implementation and Interpretation
}

\author{
Jana Gerta Backes*(D) and Marzia Traverso (D) \\ Institute of Sustainability in Civil Engineering, RWTH Aachen University, 52074 Aachen, Germany; \\ marzia.traverso@inab.rwth-aachen.de \\ * Correspondence: jana.backes@inab.rwth-aachen.de; Tel.: +49-241-80-22765
}

\begin{abstract}
The aim of this study is to define, via an online expert survey, current challenges and possible future approaches in and for the implementation, application, and interpretation of the Life Cycle Sustainability Assessment (LCSA). Using an online survey, sustainability experts from around the world were surveyed over a period of five weeks, resulting in 71 experts answering 25 questions. The experts were invited by e-mail and through networks; the online questionnaire was the preferred survey choice particularly for reasons of time, cost, and the pandemic. The survey evaluation shows that no change in LCSA is needed. Nevertheless, (1) a detailed optional baseline LCSA framework, with pre-selected fixed indicator sets, (2) a supporting optional but unified visualization tool, (3) a clear and transparent communication on assumptions, targets and system boundaries and (4) early defined stakeholders were identified as relevant for further LCSA implementation and interpretation. Due to natural subjectivity, the results of this written survey are to be understood as recommendations for action and orientation, not explicitly as a prediction. Finally, an action outlook for future LCSA-development is given.
\end{abstract}

Citation: Backes, J.G.; Traverso, M Life Cycle Sustainability

Assessment-A Survey Based Potential Future Development for Implementation and Interpretation. Sustainability 2021, 13, 13688. https://doi.org/10.3390/su132413688

Academic Editor: Miguel Brandão

Received: 13 November 2021 Accepted: 8 December 2021 Published: 11 December 2021

Publisher's Note: MDPI stays neutral with regard to jurisdictional claims in published maps and institutional affiliations.

Copyright: (c) 2021 by the authors. Licensee MDPI, Basel, Switzerland. This article is an open access article distributed under the terms and conditions of the Creative Commons Attribution (CC BY) license (https:/ / creativecommons.org/licenses/by/ $4.0 /)$.
Keywords: LCSA; survey; sustainability expert; challenge; implementation; interpretation

\section{Introduction}

Sustainability, carbon footprints and low-emission products are increasingly demanded by society [1,2]. From discussions with planners, producers and suppliers, it is evident that customers in particular [3] are increasingly broaching the subject of sustainability and expect detailed and well-founded statements on products, services and their corresponding life cycles.

A Life Cycle Sustainability Assessment (LCSA) is considered to be a valuable support for stakeholders and interested third parties with regard to sustainability assessments, footprints, emission optimization [4], and for communication to customers. The currently applied LCSA framework extends the scope of the known Life Cycle Assessment (LCA) through two additional dimensions, i.e., economic (Life Cycle Costing/LCC) and social (Social Life Cycle Assessment/S-LCA). The three methods (LCA, LCC and S-LCA) are complementary, to be applied to the same functional unit and to an equivalent system boundary. No weighting between the three pillars is permitted in the interpretation, the assessments are equivalent, and the underperformance of one pillar cannot be compensated for by another. The LCSA was initially developed in 2008/2010. [5,6] Since 2012, there has been a significant increase in LCSA studies [6], from which a variety of challenges related to LCSA emerge [7-10]. Among other things, the reviewed LCSA studies called for improvements in application, interpretation and communication, without clear indications of what those improvements might be [7].

From this, it can be hypothesized that LCSA, in its current form, is too complex and needs to be simplified/clarified to meet the demands of all stakeholders (LCSA applicants, producers, suppliers, customers). The gap between the three-dimensional sustainability assessment (LCSA) in science, and its practical application has to be closed. With the help 
of the initial questions "How is the LCSA framework applied and interpreted? Do we need a change or an improvement?" the goal of this study, via an expert online survey, is to verify or reject the hypothesis and to guide the development for common and practical applications and interpretations of LCSA.

\section{Theoretical Background}

\subsection{State-of-the-Art}

A literature review through Web of Science, Scopus, Science Direct and Google Scholar with the following individual and combined ("and", "or") search terms: LCSA, Life Cycle Sustainability Assessment, poll, survey, questionnaire, opinion, and participatory, was conducted for previously implemented and published surveys of a similar nature. After the elimination of duplicates, 13 publications remained, which indicated single terms or combinations of the mentioned search terms in the title, abstract or in key words. After a detailed examination of the content, we found that a majority of the publications used their surveys to: obtain primary data especially for LCA [11-13], to understand and set up relevance and ranking of indicators, e.g., midpoint indicators in LCA [14-16], to explicitly implement a Social Life Cycle Assessment [11,17], or to make decisions in the automotive sector regarding sustainability assessment indicators [18,19].

Jusselme et al. [20] investigated the use of LCA (only; not LCSA) in practice among architects, engineers, consultants and real estate developers. In the framework of this publication, previous studies are named which dealt with surveys and LCA use [20-24]. The objective of the research by Jusselme et al. was to introduce the life-cycle performance assessment (LCPA) to practitioners. The results show a high willingness of practitioners to consider environmental constraints in their practice, however, there is currently a low usage of LCPA software [20].

Two other studies address the use of the Life Cycle Sustainability Assessment through short and modified surveys. Pesonen and Horn [25] called for easy-to-understand communication of LCSA results back in 2012. The focus of the study is to determine whether the sustainability SWOT (Strengths, Weaknesses, Opportunities, Threats) [26] proposed by Pesonen is understood and used in the corporate world [25]. Guinee analyzed the interpretations of the International Society for Industrial Ecology (ISIE)-LCSA Section members when adopting the LCSA. All members were invited via an electronic platform and via e-mail to provide their opinion on their (preferred) definition of LCSA and their top three (scientific and/or practical) challenges for LCSA. 17 individuals responded to this invitation. Challenges such as: "How to communicate LCSA results, to and with which stakeholders, and which and how many indicators to choose" and "How to deal with value choices and subjectivity, especially in weighting" were highlighted by respondents [27].

From the literature review, it is clear that no studies have so far:

- hypothesized that LCSA in its current form is too complex and that an optional simplification may better address stakeholder demands,

- approached LCSA (not only LCA) challenges with a larger responding group,

- $\quad$ interviewed experts on sustainability assessment, life cycle technique and research in LCSA on the topic of LCSA, its use and challenges, and

- $\quad$ engaged with possible optimization approaches defined by sustainability experts.

These factors represent the unique contributions of the current publication, and at the same time it became evident from previous studies that more defined approaches are needed for common and long-term usage.

However, in the formulation and analysis of the final results of this study, there are two relevant developments that can be described as state-of-the-art and important research approaches:

Sphera published a "sphera insights paper", in which a survey was created in cooperation with the University of Esslingen in Germany to help identify and understand the maturity level of companies in the area of sustainability (not explicitly defined as, e.g., threedimensional). Altogether, 218 professionals from companies in various industries were 
surveyed-with the primary focus of LCAs and on their (professionals) corporate strategy in the context of sustainability, rather than on LCSAs and methodological application [28].

In October 2021, an invitation was sent out by PRé Sustainability for a survey [29] as part of the Horizon2020 OrientingEU project [30]. The aim of the survey was to play an important role in the development of appropriate strategies for the implementation of LCSA in the EU. In particular, experts from the fields of LCA and sustainability are asked for their opinion. This questionnaire includes 18 open and closed questions, which address all three pillars of sustainability, the individual assessments, potential users, possible barriers and especially the market potential of LCSA.

\subsection{Life Cycle Sustainability Assessment}

A framework with which sustainability performances of products and services can be analyzed, measured and potentially optimized is the Life Cycle Sustainability Assessment (LCSA). LCSA allows for an assessment over the entire life cycle of the item or service being assessed, considering the three dimensions of sustainability (environmental, economic and social). [5,6] LCSA provides a sustainability assessment of both positive and negative impacts [31-33], by combining the three techniques Life Cycle Assessment (LCA), Life Cycle Costing (LCC) and Social Life Cycle Assessment (S-LCA). A weighting between the three dimensions is not foreseen in the interpretation phase, since the three individual assessments are equivalent, and no compensation is made. [4,5] Various challenges in the application and interpretation of LCSAs became apparent $[7,8]$ —although the LCSA brings with it a great opportunity: a holistic and lifecycle-based assessment.

\subsection{Survey as Research Support}

Surveys are one of the most commonly used methods in social research. It is possible to extrapolate findings from a smaller control sample to a greater population due to the obtained data. A survey can be provided in different types of communication, with different positive and negative side effects. They can be conducted through face to face interviews, phone calls or in a written questionnaire [34].

When constructing a questionnaire to collect the written survey, a well-considered design regarding the evaluation is essential [34]. The introduction of the survey is important to ensure the practitioners attention and interest and the person and the institute that is collecting the information should be introduced in a timely manner. Participants should be briefed on the main question of the survey, and how the collected data will be processed [34,35]. A distinction is made between a quantitative or a qualitative content analysis. The quantitative content analysis aims to assign individual parts to selected, overarching categories, whereas a qualitative content analysis does not count the data, but interprets it [35]. In quantitative surveys, a large number of people are interviewed, from which a general opinion is developed. [34] By deciding on quantitative or qualitative analysis and the survey situation (written vs. oral), the content of the questionnaire can be dealt with in more detail. This includes the purpose of the survey, the target group and the expectations placed on the results [36]. Furthermore, a distinction is made between open and closed questions. In the case of written surveys, closed questions are preferable, as they make it considerably easier to evaluate questionnaires [35].

The designed survey can be delivered to the target group. It is particularly important to first consider the composition of this target group. It should be noted that the results of a survey always represent only a sample of the population. The better the sample represents the population, the more precise the inferential statistical statements about the population [35]. When the questionnaire has been processed by a sufficient sample population (target group) and data have been collected, analyzation of the data can begin. A fundamental distinction is made between inferential statistics and descriptive statistics when analyzing quantitative measurements (both are used in the current study) [37]. They merely provide an overview of characteristic values of individual variables and often represent a sound basis for further statistical calculations. These characteristic values can 
be described with the help of graphs or descriptive statistical measures (e.g., arithmetic mean or variance) [37].

\section{Materials and Methods}

Through our literature research and a workshop contribution, challenges of LCSA became evident $[7,8]$; leading to the hypothesis that LCSA in its current form is too complex a framework to meet stakeholder needs and guide decisions on this framework. A gap identified in the research was, whether these challenges also exist for sustainability experts, the availability of options on how to address these challenges in future, and how these options may look-based on several expert opinions. The methodology of a written survey is selected, since the named observations did not lead to sufficient results and the literature did not provide detailed information on the research question (Figure 1): "How is the LCSA framework applied and interpreted? Do we need a change or an improvement". In the following, the procedure for survey creation, the format selection and the sample selection are defined (Figure 1). Subsequently, the content of the questionnaire and the results will be discussed in more detail.

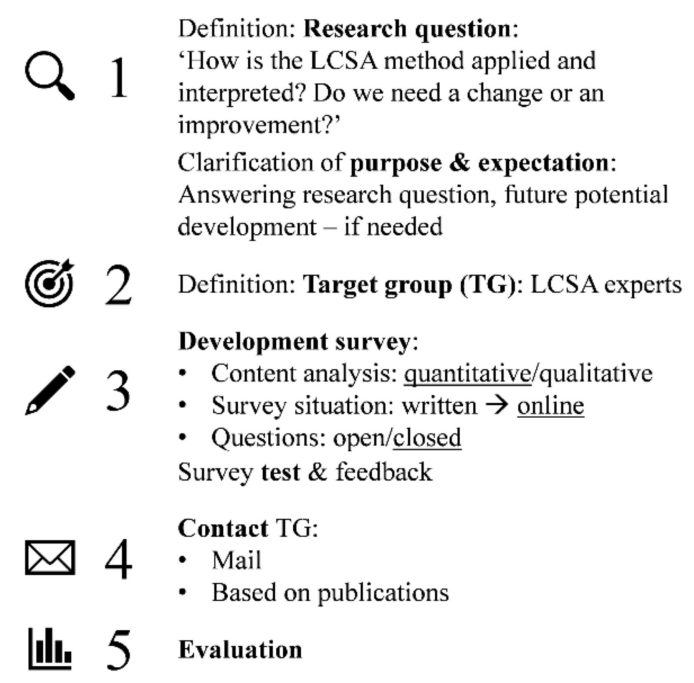

Figure 1. Methodology development (survey): LCSA implementation, application and interpretation.

\subsection{Research Question, Purpose and Expectation}

The purpose, hypothesis (current LCSA framework too complex) and research question of the survey concerned defining how LCSA is applied and whether an improvement is needed (Figure 1), which was specifically addressed to sustainability experts (sustainability assessment, life cycle technique and research in LCSA). Detailed reasons for the survey are as follows:

- $\quad$ sustainability awareness is on the rise globally,

- LCSA encompasses holistic sustainability,

- LCSA brings with it a variety of challenges,

- the simplified application and interpretation of the LCSA can be helpful for globally rising sustainability awareness.

The expectations of the survey and the responses were to clarify, support and optimize challenges defined by the literature $[7,8]$, with the help of sustainability experts.

\subsection{Target Group Definition and Contact}

The target group should have detailed knowledge in LCSA so as to reject or accept the established hypothesis and to answer detailed questions, which motivated the selection of sustainability experts. Furthermore, the target group should provide a broad spectrum of opinion and allow little interpretation in the answers. Sustainability experts were 
defined as follows: all individuals who have been certified as authors of LCSA peerreviewed publications worldwide (defined by previous literature review) up to 2020, and all individuals working at institutes or departments explicitly dealing with LCSA (according to website or research profiles).

The survey was distributed via e-mail to authors (first author e-mail addresses in publications), contacts of the Institute of Sustainability in Civil Engineering, RWTH Aachen University and to further specific and known research institutes (if not yet contacted). In addition, the questionnaire was shared through the UNEP Life Cycle Initiative network [38] and in selected sustainability assessment groups of the business network LinkedIn [39].

The invitation was distributed and published in November 2020, notifying recipients that the questionnaire could be answered online for one month (prolonged to beginning of January 2021). The invitation included information about the survey creator (author of the current study), the institution, the reason for the survey, the time period and a note on anonymity (no conclusions can be drawn about the respondents). In total, 94 experts were contacted directly by e-mail. The number of respondents reached via newsletter and postings (e.g., LinkedIn and Life Cycle Initiative) cannot be specified.

\subsection{Survey Construction}

The format of a written online survey was used to analyze the hypothesis and the research question itself (Figure 1). A written survey proved to be particularly advantageous due to the low costs involved and the greater perceived anonymity of the survey, which has a favorable effect on the willingness to provide honest information and to deal thoroughly with the problem in question. The online survey was chosen to directly contact a large group of people during the COVID19-pandemic (lockdown), and the specified target group consists of leading global experts on sustainability assessment, life cycle technique and research in LCSA. In this way, many people could be reached nationwide.

UmfrageOnline [20] was selected as an online tool for conducting the survey. The online tool is well suited for creating scientific surveys, and is a commonly used tool in research. There are several question types available, and the evaluation can be carried out in part via the tool itself [20].

A quantitative survey was conducted, and therefore it was particularly geared towards obtaining measurable responses. Thus, mainly single- or multiple-choice questions were selected, that can be evaluated using statistical methods. For further suggestions, free-text fields were created. It was understood that the questions should be as precise as possible, and the survey was kept as short as possible.

Table 1 shows the survey structure, including 25 questions and the respective answer options. The questions can be divided into five main parts, previously providing some information on the survey creator (authors of study) and time aspects (five weeks): (1) Statistics, which concerns demographics and educational background through closed questions (nominal and ratio scale, and multiple choice [36]); (2) LCSA Application, which deals with the implementation and application and experience of LCSA-experts and the three individual assessments, through closed questions; (3) SDGs, which deals with the coupling of LCSA and SDGs, through closed questions; (4) Challenges, by focusing in particular on the challenges in and with LCSA, using closed questions (rating scales) and lastly, (5) Possible solutions using open-answer options [36] were incorporated so as to include diverse opinions (Table 1).

To finalize the survey structure, it was tested internally (department) for two weeks. Feedback was gathered regarding the understanding of the questions, the structure of the survey, and the meaningfulness of the results. As a result, some changes (e.g., wording, additional or less response possibilities) were made and it was finally distributed to the defined target group. The evaluation of the results was performed partly via the tool (UmfrageOnline) itself and in MS Excel. 
Table 1. Survey design.

\begin{tabular}{|c|c|c|c|}
\hline & $\#$ & Question & Answer(s) \\
\hline \multirow{5}{*}{ (1) Statistics } & 1 & Do you work on sustainability at your job? & Yes; No \\
\hline & 2 & Do you know the LCSA framework? & Yes; No \\
\hline & 3 & What is your academic background? & $\begin{array}{l}\text { Env. Eng.; Civil Eng.; Mech. Eng.; } \\
\text { Business Admin.; Natural } \\
\text { Scientist; Georesource Scientist; } \\
\text { Social Scientist; Other (open } \\
\text { answer) }\end{array}$ \\
\hline & 4 & In which sector do you work? & $\begin{array}{l}\text { Industry; University; Research } \\
\text { Institute; Consulting; Other (open } \\
\text { answer) }\end{array}$ \\
\hline & 5 & What is your age range? & $\begin{array}{c}18-24 ; 25-29 ; 30-39 ; 40-49 ; 50-59 ; \\
>60\end{array}$ \\
\hline \multirow{4}{*}{$\begin{array}{l}\text { (2) LCSA } \\
\text { Application }\end{array}$} & 6 & Do you apply the LCSA framework to one or more of your projects? & $\begin{array}{l}\text { Never; Rarely; Sometimes; Often; } \\
\text { Always }\end{array}$ \\
\hline & 7 & Have you ever worked with either LCA, S-LCA or LCC? & Yes; No \\
\hline & 8 & Do you individually use the LCA more often than LCSA? & Yes; No \\
\hline & 9 & $\begin{array}{l}\text { In your opinion ... do the three assessments have the same relative } \\
\text { importance? ... is the non-compensation adequate (poor performance NOT } \\
\text { compensated by another better performance)?... is a unified LCSA } \\
\text { approach—-which, e.g., means using a given set of indicators and /or given } \\
\text { system boundaries—-feasible for different products? }\end{array}$ & Yes; No; No answer \\
\hline \multirow[t]{2}{*}{ (3) SDGs } & 10 & $\begin{array}{l}\text { Do you know about the } 17 \text { United Nations Sustainable Development Goals } \\
\text { (SDGs)? }\end{array}$ & Yes; No \\
\hline & 11 & Should LCSA be inspired by the SDGs and somehow embed them? & Yes; No \\
\hline \multirow{9}{*}{ (4) Challenges } & 12 & $\begin{array}{l}\text { Reviewing and comparing different LCSA studies showed that no two } \\
\text { LCSAs for the same product are exactly alike. What do you think is the } \\
\text { reason for this? (multiple selection possible) }\end{array}$ & $\begin{array}{l}\text { Different levels of maturity of the } \\
\text { three pillars; Lack of consistency } \\
\text { of LCSA; Various users; Different } \\
\text { software used; Other (open } \\
\text { answer) }\end{array}$ \\
\hline & 13 & $\begin{array}{c}\text { An equivalent execution of the three pillars (e.g., equivalent system } \\
\text { boundaries) is for you ... }\end{array}$ & $\begin{array}{c}\text { Not challenging at all; Partly } \\
\text { challenging; Very challenging; No } \\
\text { answer }\end{array}$ \\
\hline & 14 & The selection of appropriate indicators is for you ... & see \#13 \\
\hline & 15 & The data availability within the LCA is for you ... & see \#13 \\
\hline & 16 & The data availability within the LCC is for you ... & see \#13 \\
\hline & 17 & The data availability within the S-LCA is for you ... & see \#13 \\
\hline & 18 & A definition of equivalent system boundaries is for you . & see \#13 \\
\hline & 19 & An adequate presentation and interpretation of the results is for you ... & see \#13 \\
\hline & 20 & $\begin{array}{l}\text { Are there other characteristics of LCSA, we did not name or question, you } \\
\text { find challenging? }\end{array}$ & Open answer \\
\hline \multirow{5}{*}{ (5) Solution ideas } & 21 & $\begin{array}{l}\text { Should a set of predefined indicators be given for each pillar (which could } \\
\text { be used/consulted if wanted/needed)? }\end{array}$ & $\begin{array}{l}\text { Yes; No; No answer; Other (open } \\
\text { answer) }\end{array}$ \\
\hline & 22 & $\begin{array}{l}\text { Is a visualization tool necessary for interpretation and support for decision } \\
\text { making? }\end{array}$ & $\begin{array}{l}\text { Yes; No; No answer; Other (open } \\
\text { answer) }\end{array}$ \\
\hline & 23 & $\begin{array}{l}\text { Is the early integration of stakeholders relevant for the application of } \ldots \text { ? } \\
\qquad \ldots \text { LCA }, \ldots \text { LCC }, \ldots \text { S-LCA } \ldots \text { LCSA }\end{array}$ & $\begin{array}{l}\text { Not at all important; Slightly } \\
\text { important; Important; Fairly } \\
\text { important; Very important; No } \\
\text { answer }\end{array}$ \\
\hline & 24 & $\begin{array}{l}\text { Is the early integration of stakeholders relevant for the interpretation of } \ldots \text { ? } \\
\qquad \ldots \text { LCA } \ldots \text { LCC }, \ldots \text { S-LCA } \ldots \text { LCSA }\end{array}$ & see \#23 \\
\hline & 25 & Further comments, questions or research needed? & Open answer \\
\hline
\end{tabular}




\section{Results}

After a period of five weeks (End of November-January 2020/21), the survey was closed. All responses were reviewed, and the completed questionnaires were used for a result analysis and subsequent discussion.

\subsection{Population and Sample}

The exact population size of worldwide sustainability assessment experts is difficult to discern. Not all individuals are known, the definition of expert is subjective and not all experts publish regularly in their field (defined as expert). Through the preceding literature research and personal contacts of the institute, a total of 94 persons were defined as sustainability experts and contacted via e-mail (direct contact). The exact number of further participants reached through additional channels (LinkedIn, Life Cycle Initiative) is unknown. In order to define the statistically relevant sample size $(C)$ for our survey, and thus to be able to publish a representative evaluation, we used the following Equation (1):

$$
C=\frac{\frac{z^{2} * p *(1-p)}{e^{2}}}{1+\left(\frac{z^{2} * p *(1-p)}{e^{2} * N}\right)}
$$

$N=$ Population size $=94$

$e=$ Error margin $=5 \%$

$z=z$-value $=1.96$

$p=$ Standard deviation $=0.5$

The named and directly contacted 94 experts are taken as the population size $(N)$, considered to be the basic population. This represents the entire group about which or from which we ask for contributions, and who are eligible for the sample. The possibility that a given answer by a potential control group matches the population is known, and the confidence interval or error margin is labelled with " $e$ ". The standard is a $95 \%$ confidence level and a 5\% error margin. A parameter derived from the confidence level is the " $z$ value", measuring the difference between an observed statistic and its hypothetical population parameter in units of standard deviation. Due to the need for a detailed calculation explanation, we made use of the given charts $(z=1.96)$ [35]. The standard deviation " $p$ ", estimates the variance where the results are possibly located. This value is usually unknown before the execution of the survey and therefore assumed as the worst case with $50 \%(p=0.5)$ [35]. Applying Equation (1) with the named parameters, the relevant sample size $(C)$ consists of 76 individuals (Equation (2)).

$$
C=\frac{\frac{1.96^{2} * 0.5 *(1-0.5)}{0.05^{2}}}{1+\left(\frac{1.96^{2} * 0.5 *(1-0.5)}{0.05^{2} * 94}\right)}=76
$$

In January 2021, we closed the survey after collecting results from 82 respondents. Of the respondents, 11 did not complete the questionnaire, leading to a total of 71 respondents. In order to work with a fixed respondent-number, we continued with 71 answered questionnaires, even though this value is slightly below the desired target size of 76 .

\subsection{Statistics (Question 1-5)}

Of the consulted experts, $97 \%$ (71) work in the field of sustainability (assessment via MS Excel). All experts are familiar with the LCSA framework. Furthermore, $62 \%$ of the respondents have an academic background in environmental science or environmental engineering, whereas $10 \%$ have their academic background in civil engineering, $6 \%$ as mechanical engineers and $6 \%$ specialize in social sciences. The remaining $17 \%$ (Other) are 
natural scientists, such as physicist or chemist, geo-resource manager or economist and business administrator.

Overall, $41 \%$ of the respondents work at universities, $24 \%$ at research institutes such as the Max Planck or Fraunhofer Institutes. Thus, 65\% of the respondents are employed in the scientific context, whereas $17 \%$ are employed in consulting, not indicating whether this is at consulting companies or within a research context. Lastly, $10 \%$ of respondents are employed in industry, and $8 \%$ classify themselves as working in other sectors.

The majority (35\%) of all respondents are in the age group of 30-39 years, $23 \%$ are in the group of 40-49 years, 18\% were aged between 25 and 29 and $17 \%$ between 50 and 59 years. Additionally, 3-4\% are younger than 25 years or older than 59 years, which might be explained with education or retirement.

\subsection{LCSA Application (Question 6-9)}

A total of $25 \%$ of the respondents (total of 71 ) had never used the LCSA framework in past or ongoing projects, whereas $21 \%$ indicated that they rarely use LCSA, having only used the framework in one or few more projects. Thus, nearly half (46\%) of respondents did/do not use the LCSA in practice (all knowing the framework in theory). Nevertheless, $30 \%$ indicate that they sometimes apply the LCSA; the framework is used often by $15 \%$ of the participants, and 8\% always use the LCSA. Of those who always use the framework, $50 \%$ have an academic background in environmental engineering. Although almost half of the respondents do not or only rarely use the framework for projects, all respondents have already used or are using one of the individual assessments (LCA, LCC or S-LCA), revealing that the LCA is used more frequently than LCSA (89\%).

The following questions are particularly revealing with regard to the interpretation of LCSA. Experts were asked whether they think the three assessments have the same relative importance (9.1: In your opinion ... do the three assessments have the same relative importance?). It becomes evident that there is no consensus: $46 \%$ affirmed (yes, the assessments have the same relative importance), $45 \%$ denied and $8 \%$ abstained. Excluding abstentions, $51 \%$ voted yes and $49 \%$ voted no (Figure 2 ). Focusing on the different academic backgrounds, those respondents with a background in environmental engineering in particular disagree on a similar relative importance ( $56 \%$ vote no, $44 \%$ yes). Social scientists and civil engineers voted clearly with "yes" (same relative importance). With regard to the current sectoral backgrounds, industry is increasingly in favor of balance, while universities and research institutes show a tendency toward imbalances. Similar distributions can also be seen with regard to age groups, whereby the middle age groups (30-50 years) indicate no similarity $(\sim 60 \%)$, and younger and older experts hold the opposite opinion (pillars have the same relative importance).

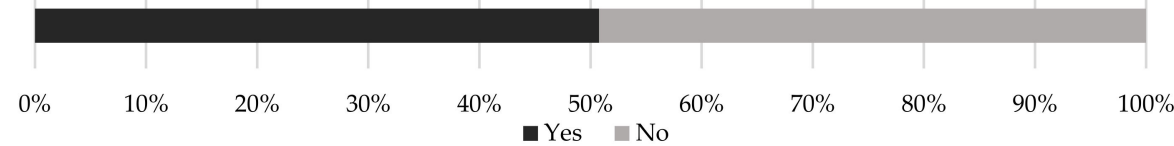

Figure 2. Three assessments having the same relative importance?

There is more agreement on the question of whether non-compensation is adequate within the LCSA framework (9.2 In your opinion ... is the non-compensation adequate?). Consequently, a poor performance of one assessment cannot be compensated for by a good or better performance of another pillar. Of the experts, $76 \%$ agree, stating that yes, the non-compensation is adequate, while one quarter vote against (24\%). Among the $24 \%$ dissenting votes, $69 \%$ have a background in environmental engineering. There is a visible correlation between university and research institutes and the "yes, non-compensation is adequate". The industrial sector is in favor of more compensation ( 1/3) (Figure 3). 


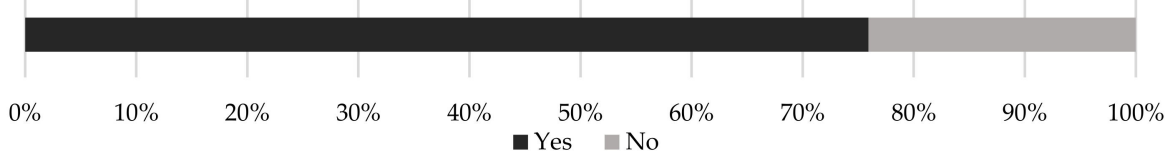

Figure 3. Non-compensation is adequate?

The question as to whether a unified and prescribed LCSA framework approach for different products would be conceivable and, more specifically, helpful, reveals a slight tendency towards a consolidated approach (9.3 In your opinion ... is a unified LCSA approach —which, e.g., means using a given set of indicators and/or given system boundaries-feasible for different products?): $61 \%$ of the experts voted in favor of a unified basis, 39\% against. In particular, experts with an academic background in the social sciences voted against a uniform approach $(67 \%)$. The industry and consulting sectors would, the results suggest, be more in favor of such standardization $(>67 \%)$, whereas no specific tendency is discernible at research institutions and universities.

\subsection{SDGs (Question 10-11)}

A total of $96 \%$ of respondents are familiar with the Sustainable Development Goals (SDGs). In particular, those respondents working in consulting, at universities and research institutes claim to have 100\% knowledge of SDGs. More relevant to the implementation and interpretation of LCSA, however, is the further question of whether the LCSA should be inspired by, or incorporate, the SDGs. Of the participants, $86 \%$ would support the combination of LCSA and SDGs. This was especially the case for those individuals working at universities (90\%) and research institutes (94\%): the support for combining LCSA and SDG is strongly provided.

\subsection{Challenges (Question 12-20)}

Questions 12-20 explicitly addressed challenges in LCSA. Considering various LCSA studies not originating from the same author, no comparisons between LCSA studies are possible $[7,8]$. According to the experts, this is due to a lack of consistency in LCSA $(29 \%)$ - even though guidelines and frameworks for LCSA are specified [5,32,33,40-43]. A further $28 \%$ state that this is due to the difference in the development of the individual pillars; software use (14\%) and different and individual users were also named as critical $(17 \%)$ (Figure 4). The open response option was used to mention the challenge of different system boundaries, the challenge of a uniform functional unit, and different assumptions made but not named (full answers in Supplementary Materials Listing S1).

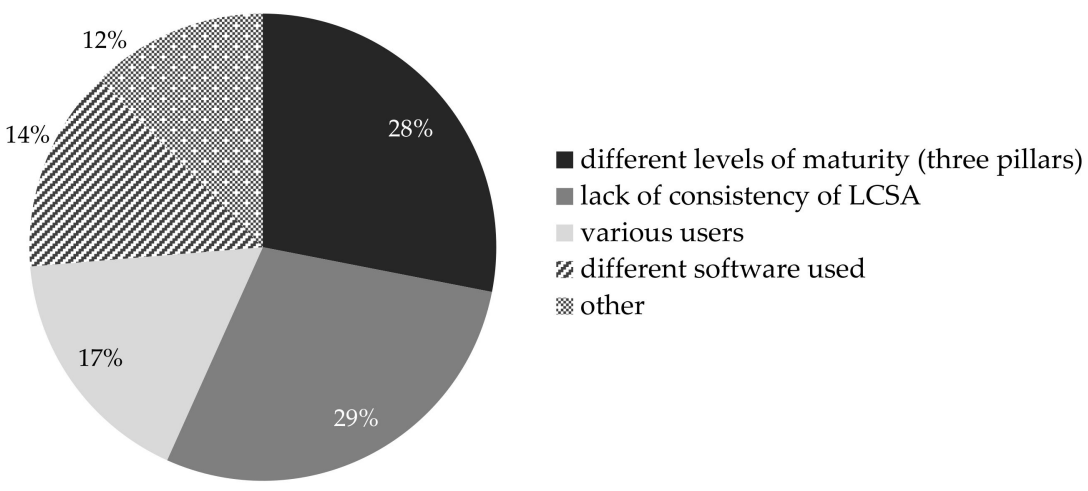

Figure 4. Reasons for difficulties in comparing LCSAs.

The considered experts were asked to rank how difficult data selection and definitions are for them (Figure 5). Figure 5 shows the mean value of the ranking. A score of 1 represents "not challenging", 2 represent the opinion "partly challenging" and 3 defines "very challenging". The evaluation of the results clearly shows that all the aspects considered 
and queried represent a challenge to the considered experts, as the mean value is $>2.18$ (partly challenging) (Figure 5).

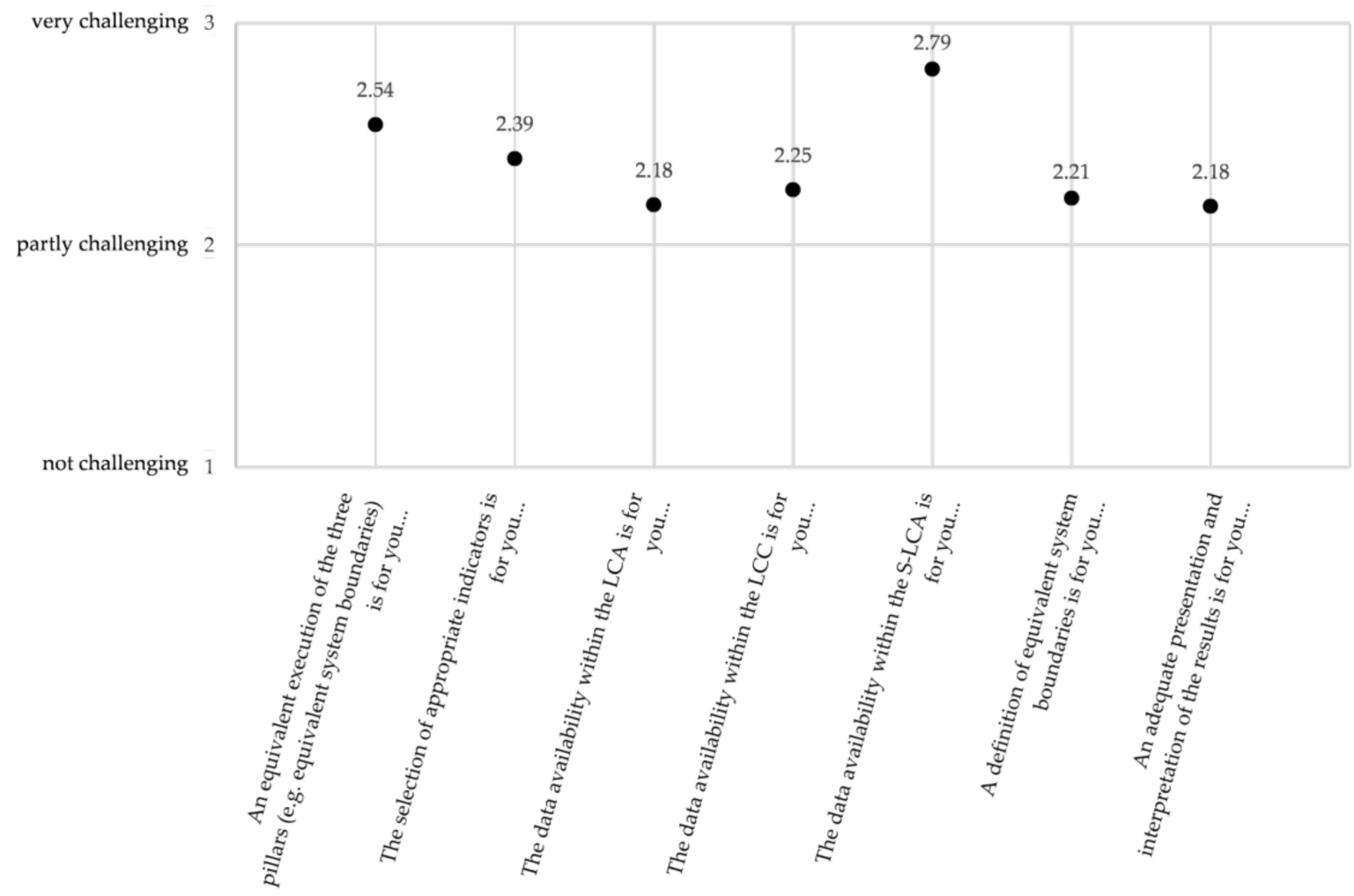

Figure 5. Challenges in LCSA-presented as mean.

Data availability in LCAs is seen as least challenging by all experts; the adequate presentation and interpretation of the results and also the definition of equivalent system boundaries further appears to be a minor hurdle (mean $=2.18$ ). Data availability in LCC and the selection of suitable indicators still do not represent the biggest challenges. Nevertheless, two aspects are named as particularly critical:

- $\quad$ equivalent execution of all three pillars $($ mean $=2.54)$ and

- data availability in S-LCA (mean = 2.79) (Figure 5).

Further focusing on correlations from educational background, working sector and age; the equivalent execution of the three pillars seems to be more challenging for the consulting sector and for younger (18-29 years) and older experts (>60) than for the average respondent; data availability is named by almost all experts as partly challenging, except for those working in industry (more challenging); in particular, data availability in S-LCA seems to be more challenging for industry and consulting than for university staff or employees of research institutes; defining equivalent system boundaries is more challenging for younger (18-29) and older (>60) age groups; and in the interpretation and presentation of the results of LCSA, the consulting sector mentioned increased challenges.

Another open question allowed for the free naming of further challenges not yet addressed ("Are there other characteristics of LCSA, we did not name or question, you find challenging?"). Besides already named aspects such as "correlation of the result to the functional unit [ ... ]", "weighting of areas of concern", "getting a set of result indicators that are relevant for decision making is not that easy", "related to local as well as global standards-comparisons and aggregation needs to be contextualized" or "different level of maturity and data availability" it became of particular importance that the interpretation and communication of LCSA is a major and much discussed challenge. In the following, a selection of given answers is quoted (anonymous replier): 
- "making clear of the indicators' meaning to 3rd parties"

- "meaning of results is quite different for all 3 pillars: LCA gives an "overall" set of results, since it all affects the environment; LCC needs to come from a certain perspective (user, producer) to provide relevant results, so data requirements can be a bit different; S-LCA is also an "overall" set, however very much subject to goals and/or cultural interpretation (for many impact categories)"

- "interpretation and transfer to meaningful, easy understandable results is challenging"

- "how relevant and significant can the results of a LCSA of one (single) product be against the background of the global challenges such as climate change, resource scarcity, poverty and social inequality that result from the parallel production and use/consumption of hundreds of thousands of products by hundreds of millions of people?" and

- "how can you sum results from an LCA, an LCC and an S-LCA [ ... ] that's just a mess and the final result means nothing in the end."

The full number of open responses is listed in the Supplementary Materials (Listing S1). Those results presented in Figure 5 confirm the hypothesis that LCSA in its current form is too complex to base decisions on and answer the demands of all stakeholders. The reason for the hypothesis-confirmation is the clear naming of challenges (Figure 5) even by sustainability experts $($ mean $>2)$.

\subsection{Solution Ideas (Question 21-25)}

To focus on future LCSA development, a few aspects were addressed, such as a preselected indicator, visualization and the early integration of stakeholders. The experts responses show that $58 \%$ are in favor of preselecting suitable indicators (Figure 6). The consulting sector in particular has great interest in this preselection (67\%). The research sector (universities and research institutes) voted with over $50 \%$ for a pre-selection. With regard to a visualization tool, $68 \%$ of all experts specified it as helpful for interpretation and decision-making support (Figure 7). Again, consultants show the greatest interest. The following additional explanatory aspects to a possible fixed set of indicators were named: "product systems are too complex, maybe if we would have it for product groups (analogy PCRs)", "they could be presented as an advice, but people could still pick or develop others if relevant" [ ... " "maybe a baseline suggestion with optional extensions" and "baselines need to be adaptable" (Figure 7) (full answers in Supplementary Materials Listing S1).

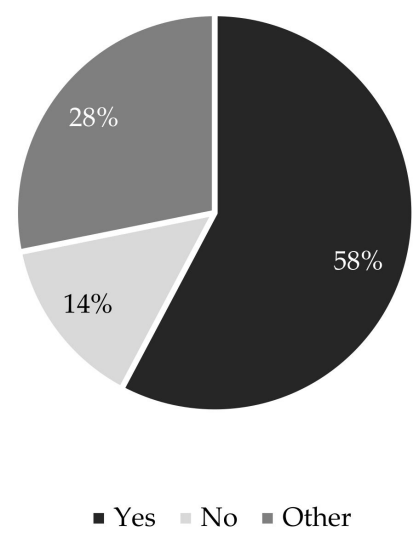

Figure 6. Given predefined set of indicators per pillar? 


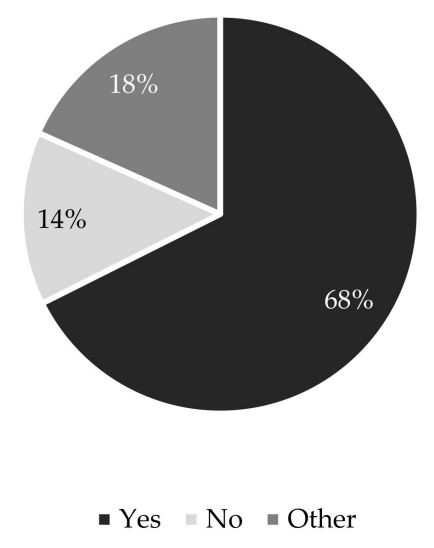

Figure 7. Visualization tool needed for interpretation and decision-making support?

To conclude the survey, the integration of stakeholders and their relevance in LCSA application and interpretation was addressed. The relevance of stakeholder engagement could be indicated from 1 ("not important") to 5 ("very important") (Figure 8). Figure 8 indicates that for the application of S-LCA and also LCSA, early stakeholder integration is considered fairly to very important. Similarly, stakeholders should be involved in the early stages of interpreting S-LCA and LCSA results. For LCA and LCC, stakeholders are named as important. In no case was the stakeholder integration considered as slightly important or not important (Figure 8) as no mean resulted in a value below 3.46 (<3 = less important).

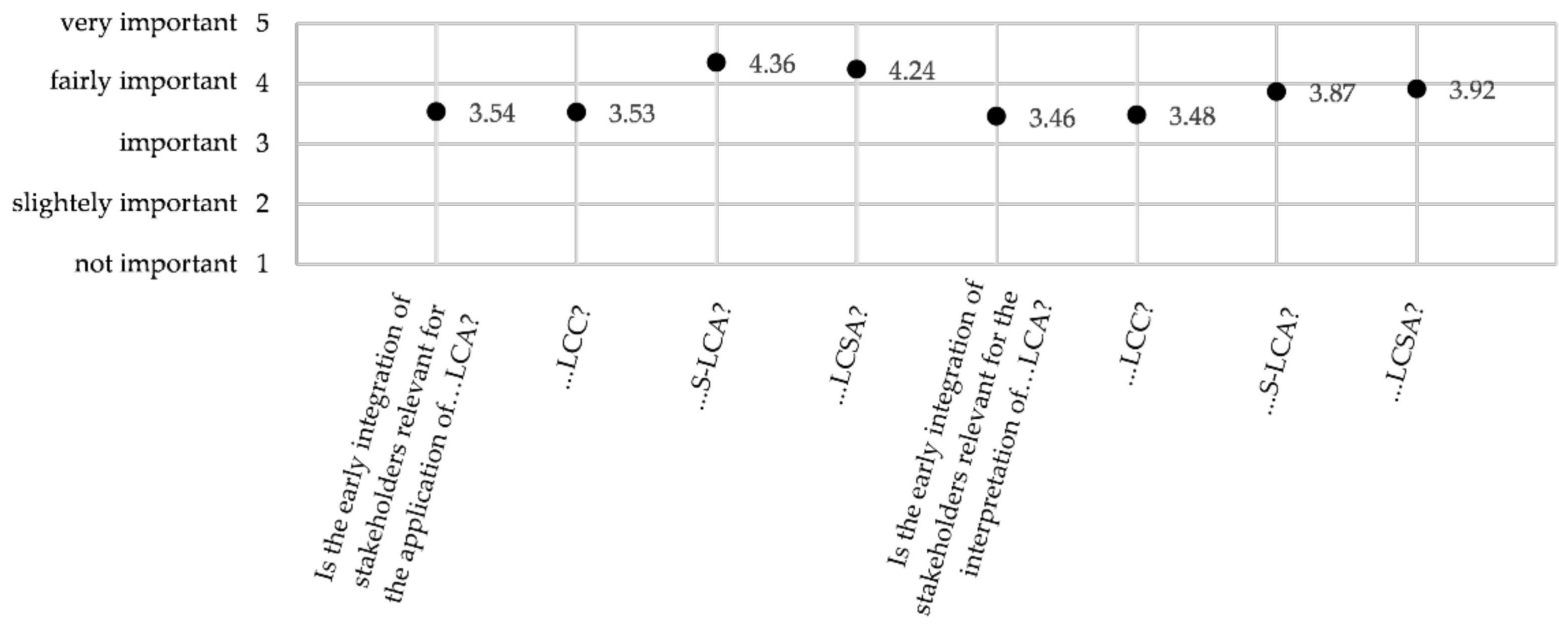

Figure 8. Stakeholder relevance-given as mean.

\section{Discussion}

The LCSA-framework has been implemented, even though it is less used than the LCA; furthermore, the challenges defined in the literature are explicit among the contacted experts-which verifies the hypothesis (framework too complex). Nevertheless, no change in the framework itself is needed (research question " [ . . ] Do we need a change or an improvement?"), but a baseline improvement especially regarding implementation and result interpretation would be an important step for future implementation and interpretation. Before concluding the survey results, the implementation of the methodology and the results, as well as limitations of the current study are to be discussed:

Design and distribution of the questionnaire are somehow subjective, since the direct distribution of the survey to the experts was based on contacts and articles read, although networks with broad access (LinkedIn and Life Cycle Initiative) were used. Furthermore, it cannot be said with certainty that the respondents did not respond randomly or whether they made false statements. A majority of the experts have their academic background 
in environmental engineering (62\%), yet $10 \%$ are civil engineers, which in sustainability topics might be unusual (small amount of LCSA studies focusing on construction [7]). Similarly, $65 \%$ of experts are actually employed in research-which was a target of the survey, but may also introduce a bias as sustainability experts do not necessarily work in a research context. These findings may be due to the authors' current research environment and background. The questions themselves have been developed by the authors on the basis of literature research and a workshop in the context of a previous conference (LCIC Conference 2020 [44]). This personal and subjective development might become apparent by illustrating the duplication of questions (fixed set of indicators could be understood similarly to prescribed approach). Nevertheless, the structure and distribution are presented in a completely transparent manner, for optimization and replication by the reader at any time.

The sample population does not represent the basic population with absolute certainty (Section 4.1). Nevertheless, due to the high number of participants (71 respondents) and the broad demographic structure, the results of this written survey can be understood as providing recommendations for action and orientation, but not explicitly as a prediction for the ensuing results. If the authors had defined $N$ as, e.g., 86 , assuming that some experts do not read or receive their e-mails, etc., then the representative sample size would be 70 and thus we would have a numerically representative size. If $N$ had been unknown and not defined, the representative sample size would have resulted in a representative sample of 384 (Equation (3)).

$$
C=\frac{z^{2} * p *(1-p)}{e^{2}}=384
$$

Regarding the LCSA framework implementation, it became evident that individual pillars are used more frequently, with LCA being the most commonly used and presenting the least challenges in application (most developed one). The main users of LCSA are environmental engineers, which can be seen as positive due to their expected background expertise; on the other hand, this might lead to a one-dimensional view and interdisciplinarity is missing-which could present a disadvantage, especially in interpretation of results and communication.

There is disagreement about whether all three pillars have the same relative importance. This challenge is also reflected in free text fields by statements such as "the equivalent execution of 3 pillars" or "standardization is needed". Nevertheless, compensation should be avoided. At this point, there is a gap in the survey, since the topic of weighting was not further questioned, which could, however, explain the gap between the two contrary statements (majority: pillars are named as not being equivalent, at the same time compensation should be avoided according to experts).

Of the respondents, $61 \%$ call for a unified and prescribed LCSA approach, as well as a basis of selected and predefined indicators (58\%). In particular, individuals employed in industry and consulting express their support in this regard-which might be driven by the increasing interest of the global community and third parties. In addition, $86 \%$ support the combination of LCSA and SDGs, eventually leading to present and future additional challenges [45]. Again, a more in-depth and explicit survey would have been beneficial (limitation), investigating the way a unified and prescribed approach may present itself; which indicators provide an important and meaningful basis for experts and yet do not overwhelm uninformed decision-makers; and how a link between LCSA and SDGs may present. These aspects (unified, given indicators, LCSA and SDG connection) should be questioned in a more detailed manner in the near future to build up a detailed solution approach (verifying hypothesis). A solution approach on part of single authors could be configured, but might not reflect a universally valid approach.

The involvement of stakeholders is considered relevant at all times. In future research, more detailed questions should be asked about how exactly stakeholders are to be involved, as well as who is defined as a stakeholder, why, and at what point in time they are to be contacted with which information and potential tasks. 
Further, the open answer, stating that relevant information is "not named/missing decisions/assumptions" is somehow surprising. As an LCSA applicant, or even a user of the individual pillars (sustainability expert), reproducibility should be a top priority in order to anchor framework and methods in science, business and politics in long term and to integrate sustainability as a science-based aspect in day-to-day business.

Experts working in industry describe data availability/collection as particularly challenging - primary data often comes from industry. In our opinion, this is a contradiction which could be resolved or at least reduced with education or a unified and prescribed LCSA approach, as well through the provision of basic indicators.

Education and experience could also provide an explanation for conspicuities in particularly young and particularly old age groups: for example, it appears that the equivalent execution of the three pillars is more challenging for younger (18-29 years) and older experts $(>60)$ than for the average respondent, and the definition of equivalent system boundaries is more complex for younger (18-29) and older $(>60)$ respondents.

\section{Further Research Surveys and Main Results-LCSA in the Construction Sector}

In addition to the presented survey, two further, smaller surveys were conducted as study papers in a similar time frame, also via UmfrageOnline. In this respect, a brief overview is given, as it reinforces the experts' statements (current survey with sustainability experts) in parts and highlights challenges, especially in industry (construction sector). The reasons for conducting the online questionnaire and the structure of the two questionnaires are similar to those detailed previously. For these surveys, it was of great relevance to identify whether LCSA is used in the construction sector, whether it is known, whether individual assessments are increasingly being used, and whether challenges exist-focusing on the same hypothesis. The construction industry provides a large number of jobs and is responsible for $10 \%$ of global gross domestic product (GDP); at the same time, this industry contributes to resource depletion, energy consumption and $\mathrm{CO}_{2}$ emissions [46,47]. A previous literature review of LCSA studies in the construction sector, revealed that construction projects include a variety of impact criteria that do not focus on sustainability. Only $11 \%$ of the literature considered refers to LCSAs [7]. Consequently, the target groups within the scope of these studies were (1) current and (2) future professionals in the construction industry. The (1) current decision makers (DMs) in the construction sector were asked to provide information on whether and to what extent practitioners (construction sector) are aware of LCSA and what opportunities and challenges exist; (2) future decision makers were defined as mainly environmental and civil engineering students. As future decision maker (DM) in the construction sector, the students have a special importance in the field of sustainability assessment.

Within first group of decision makers, $57 \%$ of all respondents (79 in total) stated that sustainability is a focus in their company, and $94 \%$ of them describe LCA as important and relevant for the construction sector. However, over $60 \%$ have never conducted a LCA (contradiction). LCC and S-LCA have never been assessed by any of the decision makers surveyed. When LCA was performed, it was at the request of customers. When asked about LCSA, $51 \%$ of all respondents indicated that they had heard of LCSA; no participants have yet assessed or instructed an LCSA. Furthermore, decision makers seem to ignore the set equivalence of the three pillars [5,6], and ranked them in the following way: economic > environmental > social (pillar) [3].

Of the second group, comprising future decision makers (143 students, higher education than third bachelor semester), $62 \%$ named sustainability as a general focus of their study program. Nevertheless, $38 \%$ of respondents are aware of LCSA, while in contrast, all respondents call for more LCAs to be conducted in the construction sector (knowledge vs. requirement). Less than $10 \%$ of respondents have conducted a sustainability assessment (either LCA, LCC, S-LCA or LCSA). More than 70\% of students desire more courses and seminars on sustainability, as there is a desire for more hands-on experience with sustainability assessments (relating to sustainability expert survey: education; young age group). 
There is also a demand for sustainability assessments to be explicitly addressed not only in the construction industry, but also for cross-topic and cross-disciplinary events.

This brief insight is not used for the detailed statistical and survey related aspects. It does, however, underline that sectors such as the construction sector increasingly need a predefined set of indicators and further guidance on LCSA or LCA, S-LCA and LCC implementation, in a more simplified form than the already published guidelines. The interest of customers will increase in future [1,2], which will require the implementation of sustainability assessments. Students appreciate the interdisciplinary preparation and teaching, which especially puts the education sector in duty to address global challenges—using a structured and low-barrier entrance with LCSA.

\section{Conclusions}

In the current study, based on the hypothesis that the Life Cycle Sustainability Assessment (LCSA) framework is too complex to base decisions on, and to address stakeholder demands, an online survey was distributed to sustainability experts. The aim was to understand how the LCSA framework is used and interpreted among experts and whether any change or improvement in terms of implementation, application and interpretation is needed to guide LCSA towards becoming a commonly used and practical decision-making framework.

In a timeframe of five weeks, experts were asked (online, written survey) about LCSA implementation, challenges and possible solutions. The questionnaire consisted of 25 questions, that were answered by 71 experts. Most of the experts have their academic background in environmental engineering. With regard to change or improvement, the respondents did not highlight the need for framework change. However, the experts defined the need for a uniform and structured LCSA-basis, which can optionally be used to standardize application and interpretation. The main aspects resulting from the survey can be summarized as follows: Challenges/barriers that were identified in the implementation of LCSA include: different levels of maturity of the three assessments, the equivalent execution of the three pillars, lack of consistency of LCSA, and data availability (mainly in S-LCA), all of which were identified as particularly critical (questions 12-20). With regard to communication, it is evident that challenges arise with regard to the selection of indicators, the dissemination of indicator content to non-experts, and the transformation of results into simple and easy-to-understand results. Future solution/drivers were also identified, and $61 \%$ of the experts mention a unified LCSA approach as a future approach (question 9.3). This includes, for example, a fixed pre-selection of indicators and/or the clear underlining by a visualization tool (questions 21-25). Furthermore, the combination of LCSA and SDGs is considered relevant (questions 10 and 11).

Due to the fact that a survey is subjective by nature, the results of this written survey are to be understood as recommendation for action and orientation, not explicitly as a prediction.

Finally, based on the findings, the following recommendations are made to create a future LCSA framework that can guide decision makers and incorporate policy initiatives:

1. A unified basis approach for LCSAs, with a pre-selection of basis indicators (eventually according to Product Category Rules) — that is not mandatory to use, and includes:
a. clear communication of goal, assumptions and data selection (replicable)
b. no compensation, no weighting
c. relate to SDGs
d. idea: start with LCA-basis-unification, as this is the most common and best- known assessment.

2. Define relevant stakeholder for, e.g., a specific sector/project and integrate them as early as possible.

3. Clearly explain how to proceed with S-LCA and LCC - possibly with a focus on hotspots and production costs in unified basis approach, to build consistency and minimize the method-entry-barrier. 
4. Identify and make use of one common and easy to understand visualization tool (if possible, use or further develop those that already exist $[6,48,49])$.

Supplementary Materials: The following are available online at https:/ / www.mdpi.com/article/10.339 0/su132413688/s1, Listing S1. Open Answers: All open answers of the experts are listed.

Author Contributions: Conceptualization, J.G.B.; methodology, J.G.B.; software, J.G.B.; validation, J.G.B.; formal analysis, J.G.B.; investigation, J.G.B.; resources, M.T.; data curation, J.G.B.; writing-original draft preparation, J.G.B.; writing-review and editing, J.G.B., M.T.; visualization, J.G.B.; supervision, M.T.; project administration, J.G.B.; funding acquisition, M.T., J.G.B. All authors have read and agreed to the published version of the manuscript.

Funding: This research was funded by the German Research Foundation (DFG), as part of the Sonderforschungsbereich/Transregio 280 (SFB/TRR 280) “Konstruktionsstrategien für materialminimierte Carbonbetonstrukturen" / "Design Strategies for Material-Minimized Carbon Reinforced Concrete Structures" (Subproject E01, project number 417002380).

Institutional Review Board Statement: The study was conducted according to the guidelines of the Declaration of Helsinki, and approved by the Ethics Committee of RWTH Aachen University (Ethik-Kommission an der Medizinischen Fakultät der RWTH Aachen) (protocol code: EK 462/21 and date of approval: 26th November 2021).

Informed Consent Statement: Not applicable.

Data Availability Statement: The data presented in this study are available in the study and its Supplementary.

Acknowledgments: This research was funded by the German Research Foundation (DFG), as part of the Sonderforschungsbereich/Transregio 280 (SFB/TRR 280) "Konstruktionsstrategien für materialminimierte Carbonbetonstrukturen" / "Design Strategies for Material-Minimized Carbon Reinforced Concrete Structures" (Subproject E01, project number 417002380). The financial support by the German Research Foundation (DFG) is gratefully acknowledged.

Conflicts of Interest: The authors declare no conflict of interest.

\section{References}

1. Wöhlert, S. Konsumenten Fordern Mehr Nachhaltigkeit 2020. Available online: https://dievolkswirtschaft.ch/de/2020/11/ konsumenten-fordern-mehr-nachhaltigkeit/ (accessed on 18 October 2021).

2. Reuters. Unternehmen fordern mehr Klimaschutz 2021. Available online: https://www.boersen-zeitung.de/unternehmenfordern-mehr-klimaschutz-9225fdf8-2a70-11ec-a381-7bc6f1096187 (accessed on 18 October 2021).

3. Backes, J.G.; Traverso, M. Life Cycle Sustainability Assessment in the Construction Sector - Actual Application and Future Outlook. In Proceedings of the 10th International Conference on Life Cycle Management, Virtual Conference. 5-8 September 2021.

4. Zamagni, A.; Pesonen, H.-L.; Swarr, T. From LCA to Life Cycle Sustainability Assessment: Concept, practice and future directions. Int. J. Life Cycle Assess. 2013, 18, 1637-1641. [CrossRef]

5. Kloepffer, W. Life cycle sustainability assessment of products. Int. J. Life Cycle Assess. 2008, 13, 89-95. [CrossRef]

6. Finkbeiner, M.; Schau, E.M.; Lehmann, A.; Traverso, M. Towards Life Cycle Sustainability Assessment. Sustainability 2010, 2 3309-3322. [CrossRef]

7. Mwamahonje, A.; Eleblu, J.S.Y.; Ofori, K.; Feyissa, T.; Deshpande, S.; Garcia-Oliveira, A.L.; Bohar, R.; Kigoni, M.; Tongoona, P. Introgression of QTLs for Drought Tolerance into Farmers' Preferred Sorghum Varieties. Agriculture 2021, 11, 883. [CrossRef]

8. Valdivia, S.; Backes, J.G.; Traverso, M.; Sonnemann, G.; Cucurachi, S.; Guinée, J.B.; Schaubroeck, T.; Finkbeiner, M.; LeroyParmentier, N.; Ugaya, C.; et al. Principles for the application of life cycle sustainability assessment. Int. J. Life Cycle Assess. 2021, 26, 1900-1905. [CrossRef]

9. Visentin, C.; Trentin, A.W.D.S.; Braun, A.B.; Thomé, A. Life cycle sustainability assessment: A systematic literature review through the application perspective, indicators, and methodologies. J. Clean. Prod. 2020, 270, 122509. [CrossRef]

10. Anand, C.K.; Amor, B. Recent developments, future challenges and new research directions in LCA of buildings: A critical review. Renew. Sustain. Energy Rev. 2017, 67, 408-416. [CrossRef]

11. Chen, W.; Holden, N.M. Tiered life cycle sustainability assessment applied to a grazing dairy farm. J. Clean. Prod. 2018, 172, 1169-1179. [CrossRef]

12. Pizzirani, S.; McLaren, S.; Forster, M.E.; Pohatu, P.; Porou, T.T.W.; Warmenhoven, T.A. The distinctive recognition of culture within LCSA: Realising the quadruple bottom line. Int. J. Life Cycle Assess. 2016, 23, 663-682. [CrossRef]

13. De Luca, A.I.; Falcone, G.; Stillitano, T.; Iofrida, N.; Strano, A.; Gulisano, G. Evaluation of sustainable innovations in olive growing systems: A Life Cycle Sustainability Assessment case study in southern Italy. J. Clean. Prod. 2018, 171, 1187-1202. [CrossRef] 
14. Dinh, T.H.; Dinh, T.H.; Götze, U. Integration of Sustainability Criteria and Life Cycle Sustainability Assessment Method into Construction Material Selection in Developing Countries: The Case of Vietnam. Int. J. Sustain. Dev. Plan. 2020, 15, $1145-1156$. [CrossRef]

15. Janjua, S.Y.; Sarker, P.K.; Biswas, W.K. Development of triple bottom line indicators for life cycle sustainability assessment of residential bulidings. J. Environ. Manag. 2020, 264, 110476. [CrossRef]

16. Maleki, R.; Atabi, F.; Jozi, S.A.; Arjomandi, R.; Mansouri, N. Sustainable Environmental Management using Life Cycle Sustainability Assessment Model in Petrochemical Industry. Pollution 2020, 6, 337-351.

17. Grubert, E. Rigor in social life cycle assessment: Improving the scientific grounding of SLCA. Int. J. Life Cycle Assess. 2018, 23, 481-491. [CrossRef]

18. Tarne, P.; Lehmann, A.; Kantner, M.; Finkbeiner, M. Introducing a product sustainability budget at an automotive company-one option to increase the use of LCSA results in decision-making processes. Int. J. Life Cycle Assess. 2018, 24, 1461-1479. [CrossRef]

19. Tarne, P.; Lehmann, A.; Finkbeiner, M. Introducing weights to life cycle sustainability assessment-how do decision-makers weight sustainability dimensions? Int. J. Life Cycle Assess. 2018, 24, 530-542. [CrossRef]

20. Jusselme, T.; Rey, E.; Andersen, M. Surveying the environmental life-cycle performance assessments: Practice and context at early building design stages. Sustain. Cities Soc. 2019, 52, 101879. [CrossRef]

21. Hofstetter, P.; Mettier, T.M. What Users Want and May Need. J. Ind. Ecol. 2003, 7, 79-101. [CrossRef]

22. Pizzol, M.; Laurent, A.; Sala, S.; Weidema, B.; Verones, F.; Koffler, C. Normalisation and weighting in life cycle assessment: Quo vadis? Int. J. Life Cycle Assess. 2017, 22, 853-866. [CrossRef]

23. Sibiude, G.; Lasvaux, S.; Lebert, A.; Nibel, S.; Peuportier, B.; Bonnet, R. Survey on LCA Results Analysis, Interpretation and Reporting in the Construction Sector. In Proceedings of the World Sustainable Building 2014 Conference, Barcelona, Spain, 28-30 October 2014; pp. 23-30.

24. Cooper, J.S.; Fava, J.A. Life-Cycle Assessment Practitioner Survey: Summary of Results. J. Ind. Ecol. 2008, 10, 12-14. [CrossRef]

25. Pesonen, H.-L.; Horn, S. Evaluating the Sustainability SWOT as a streamlined tool for life cycle sustainability assessment. Int. J. Life Cycle Assess. 2013, 18, 1780-1792. [CrossRef]

26. Pesonen, H.-L. Sustainability SWOTs - New Method for Summarizing Product Sustainability Information for Business Decision Making. In Proceedings of the 3rd International Conference on Life Cycle Management, Zurich, Switzerland, 27-29 August 2007.

27. Stahel, W.R.; Clift, R. Stocks and Flows in the Performance Economy. In Taking Stock of Industrial Ecology; Clift, R., Druckman, A., Eds.; Springer: New York, NY, USA, 2016; Chapter 7; pp. 137-158. [CrossRef]

28. Sphera. Sustainability Survey 2021. Available online: https://3gry456jeet9ifa41gtbwy7a-wpengine.netdna-ssl.com/wp-content/ uploads/2021/09/Sphera-Insights-Sustainability-Report-2021-final.pdf (accessed on 8 November 2021).

29. PRé Sustainability. ORIENTING LCSA Market Potential Survey 2021. Available online: https://forms.office.com/pages/ responsepage.aspx?id=TenODNCsoEmo_pred5MzkfrT3VmAIeFGnE1dnu8QjedURUtBWVRPMIUxUzFWTU5MNTgwRUZQQ0 taNC4u (accessed on 8 November 2021).

30. ORIENTING. ORIENTING Project 2021. Available online: https:/ / orienting.eu/ (accessed on 8 November 2021).

31. Benoît, C.; Norris, G.A.; Valdivia, S.; Ciroth, A.; Moberg, А̊; Bos, U.; Prakash, S.; Ugaya, C.; Beck, T. The guidelines for social life cycle assessment of products: Just in time! Int. J. Life Cycle Assess. 2010, 15, 156-163. [CrossRef]

32. Norris, C.; Traverso, M.; Neugebauer, S.; Ekener, E.; Schaubroeck, T.; Garrido, S.; Berger, M.; Valdivia, S.; Lehmann, A.; Finkbeiner, M.; et al. Guidelines for Social Life Cycle Assessment of Products, 2nd ed.; UNEP: Nairobi, Kenya, 2020.

33. Andrews, E.S.; Barthel, L.-P.; Beck, T.; Benoît, C.; Ciroth, A.; Cucuzzella, C.; Gensch, C.-O.; Hébert, J.; Lesage, P.; Manhart, A.; et al. Setac Life Cycle Initiative. In Guidelines for Social Life Cycle Assessment of Products; UNEP: Nairobi, Kenya, 2009.

34. Steiner, E.; Benesch, M. Datenerhebung: Die schriftliche Befragung (Fragebogen). In Der Fragebogen; UTB GmbH: Stuttgart, Germany, 2018. [CrossRef]

35. Döring, N.; Bortz, J. Forschungsmethoden und Evaluation in den Sozial- und Humanwissenschaften; Springer-Lehrbuch: Berlin/Heidelberg, Germany, 2016; ISBN 978-3-642-41089-5.

36. Hollenberg, S. Fragebögen-Fundierte Konstruktion, Aachgerechte Anwendung und Aussagekräftige Auswertung; Springer: Wiesbaden, Germany, 2016. [CrossRef]

37. Steiner, E.; Benesch, M. Elementare Definitionen. In Der Fragebogen; UTB GmbH: Stuttgart, Germany, 2018. [CrossRef]

38. Life Cycle Initiative. Available online: https: / / www.lifecycleinitiative.org/ (accessed on 5 October 2021).

39. LinkedIn 2021. Available online: https:/ / www.linkedin.com (accessed on 18 October 2021).

40. International Organization for Standardization. Environmental Management_Life Cycle Assessment_Principles and Framework; ISO 14040:2006; International Organization for Standardization: Geneva, Switzerland, 2006.

41. International Organization for Standardization. Environmental Management—Life Cycle Assessment-Requirements and Guidelines; ISO 14044:2006/Amd 1:2017; International Organization for Standardization: Geneva, Switzerland, 2018.

42. Swarr, T.E.; Hunkeler, D.; Klöpffer, W.; Pesonen, H.L.; Ciroth, A.; Brent, A.C.; Pagan, R. Environmental Life Cycle Costing: A Code of Practice; Society of Environmental Toxicology and Chemistry (SETAC): Brussels, Belgium, 2011.

43. Swarr, T.E.; Hunkeler, D.; Klöpffer, W.; Pesonen, H.-L.; Ciroth, A.; Brent, A.; Pagan, R. Environmental life-cycle costing: A code of practice. Int. J. Life Cycle Assess. 2011, 16, 389-391. [CrossRef]

44. Backes, J.G.; Traverso, M. Workshop: A new methodology being no more contemporary? - How to interpret and weight the out-comes of LCSA. In Proceedings of the 2nd Life Cycle Innovation Conference, Virtual Conference. 26-28 August 2020. 
45. Backes, J.G.; Traverso, M. Life Cycle Sustainability Assessment as a metrics towards SDGs Agenda 2030. Curr. Opin. Green Sustain. Chem. 2022, 33. accepted with revision.

46. Dong, Y.H.; $\mathrm{Ng}$, S.T. A modeling framework to evaluate sustainability of building construction based on LCSA. Int. J. Life Cycle Assess. 2016, 21, 555-568. [CrossRef]

47. Janjua, S.Y.; Sarker, P.K.; Biswas, W.K. Sustainability assessment of a residential building using a life cycle assessment approach. Chem. Eng. Trans. 2019, 72, 19-24. [CrossRef]

48. Traverso, M.; Finkbeiner, M.; Jørgensen, A.; Schneider, L. Life Cycle Sustainability Dashboard. J. Ind. Ecol. 2012, 16, 680-688. [CrossRef]

49. Corona, B.; Miguel, G.S. Life cycle sustainability analysis applied to an innovative configuration of concentrated solar power. Int. J. Life Cycle Assess. 2018, 24, 1444-1460. [CrossRef] 